ence in the laboratories may suggest modifications. The several views are unified at the Research Board. After it is agreed, the strategic plan can be detailed, based on the accumulated records of work which should be compiled at the laboratories and from which the effort and cost of investigations similar in nature can be deduced.

The value of such a strategic plan is that it should show realistically how many development projects can be dealt with within existing strength, when key decisions are necessary related to overall construction or production plans, the expected utilization of labour and the possible need for recruitment. After formal executive approval, it should be distributed to senior members of other branches to apprise them of the extent of effort applied on their behalf and to allow the opportunity for further discussion on overall policy. Executively, it provides the key to effective utilization of effort.

Where a number of experimental establishments is involved, an important functional responsibility is to ensure that all work is co-ordinated according to the agreed plan, and all but necessary duplication avoided. Constant discussion with the experimental workers should mean that new findings are applied expeditiously even before publication.

Where facilities to cater for some aspect do not exist anywhere in the organization, arrangement for extra-mural research to be carried out by some other organization is appropriate to functional respons. ibility, although the management of such work when initiated is executive.

During the preparation of the budget submissions, the co-ordination of financial requirements can be made a functional responsibility, and thus the various schemes from the separate establishments can be dovetailed before consideration by the Research Board. This is a logical consequence of strategic planning.

Where the organization is large, strategic planning will embrace all aspects in all establishments or groups. Tactical planning applies only to the establishment, group or section the effort of which is under consideration, and is necessary to the efficient discharge of the executive responsibility of management.

\section{INTERNATIONAL PROTECTION OF BIRDS}

$\mathrm{T}$

HE sixth Conference of the European Continental Section of the International Committee for Bird Preservation was held in the village of Beetsterzwaag, Friesland, Holland, during June 3-7, under the chairmanship of Dr. Boje Benzon (Den. mark). The meeting was attended by delegates of the national sections of Austria, Belgium, Denmark, France, Germany, Great Britain and Northern Ireland, Italy, Netherlands, Norway, Sweden and Switzerland, together with representatives of the International Union of Biological Sciences, the Conseil International de la Chasse and an observer from Luxembourg.

One of the most important achievements of the European Section was the drawing up of an International Convention for the protection of birds which was signed ad referendum by the representatives of twelve European powers in Paris in 1950. Switzerland was the first country to ratify it in 1954, and was followed by the Netherlands, Spain, Belgium and Iceland; but in spite of the new Bird Protection Act of 1954 on which great hopes were placed, the United Kingdom Government has still expressed inability to ratify. This Convention is a revision of the Paris Convention of 1902 , which was confined to birds useful to agriculture only, and embraces the modern conception of bird protection-that as a main principle all birds should be protected-excep. tions being made for species which are considered harmful, and for special circumstances and conditions. After a frank discussion, the general feeling of the meeting was expressed in a resolution pointing out that certain governments might be hesitant to ratify the Convention on account of minor differences, and directing attention to the 'escape clauses' provided.

In another international agreement, vitally affect. ing birds, the International Convention for the Prevention of the Pollution of the Sea by Oil, the United Kingdom, however, has taken the lead, for it was at the Inter-Governmental Conference convened in London in 1954 that this Convention was drawn up. The United Kingdom was the first country to ratify it, in 1955 ; the representatives of Denmark, the German Federal Republic and Sweden reported that their Governments had since taken this step, while others stated that their respective Governments were in the process of passing, or on the point of introducing, legislation to enable ratification. Thus after more than thirty-five years, during which thousands of sea-birds have perished annually, a concrete step forward to combat this evil has been made.

The diminution of the birds of prey all over Europe is causing concern, and it was unanimously agreed that these birds were in need of better protection and that to achieve this end education as to their value was urgently required. In this matter Great Britain, where full protection is accorded to all birds of prey except the sparrowhawk (Accipiter nisus), is outdistanced only by The Netherlands, where all birds of prey, without exception, are protected. This overall protection was recently given in Holland as a result of the frequent mistakes which had been made in shooting other species which are difficult to distinguish from the sparrowhawk.

Reports on the diminution of the white stork were given from several countries, though from Austria and Hungary came news of an increase in numbers. The causes of the diminution of this large white and black bird are varied; as with most species, more intensive cultivation being considered one of the prime reasons. It was stated that large numbers of storks meet their death by flying into overhead wires and tall chimneys, and France and Spain were blamed for the fact that though the stork is legally protected in those countries, the law is not enforced and large numbers are shot. It was alleged that in Spain hunters especially aim at killing ringed storks as they like to collect the rings as trophies, and in view of this it has been decided in the Netherlands to cease all ringing of young storks for the present. A French speaker stated that, from his personal observations, white storks certainly did not appear to be diminishing in Central Africa, and put forward the suggestion that numbers of this species might possibly be losing their habit of northerly migration. In Holland and other countries suitable platforms have been erected to encourage storks to nest, and this scheme has already met with encouraging success; it would appear, however, that the birds are becoming lazy, 
as it has been observed that they prefer nests already prepared to a mere nesting platform.

The use of pesticides and their effect on wild life was dealt with at length by speakers from The Netherlands and Germany and supported by statements from Belgium, France, Great Britain, Sweden and Switzerland. The great difficulties of this problem were fully realized and it was agreed that in view of the time required fully to assess the effects of pesticides on wild life and the constantly changing situation with regard to the production of these substances, this subject should be kept permanently on the agenda of the Committee. In the meantime, a resolution was passed urging all Governments to take the necessary steps to prohibit the further use or sale of any pesticide which had been proved to be excessively destructive to birds and other forms of wild life.

Among other subjects discussed at the meeting were the control of the export and import of wild birds' eggs, birds which are a menace to other species, the protection of the skylark and the effect of shooting during severe frost. National representatives also reported on the establishment of new bird reserves, particularly on migration routes, and the state of bird preservation in their respective countries.

Throughout the meeting it was evident how difficult it is for one country to pass and maintain protective measures unless her neighbours do likewise, and that, to ensure the effective preservation of birds, international collaboration is imperative. But the cordial atmosphere which prevailed, and the obvious desire of all national representatives, without exception, to co-operate to the fullest extent, were striking features of the discussions.

Immediately before the Conference, a meeting of the Executive Board of the International Wildfowl Research Bureau (a branch of the International Committee for Bird Preservation) was held under the chairmanship of the honorary director, Dr. Edward Hindle, at which the problems of the conservation of wildfowl, the Anatidae in particular, were dealt with. PhyILIS BARCLAY-SMITH

\section{INTERNATIONAL SCIENTIFIC RADIO UNION}

$\mathrm{A}$

$\mathrm{N}$ account of the eleventh general assembly of the International Scientific Radio Union, held in The Hague during August 23-September 2, 1954 has already appeared in Nature (September 3, 1955, p. 451); and this, together with a later account (Nature, April 7, p. 652), dealt with three (Parts 1, 4 and 8) of the eight parts of Vol. 10, which forms the published proceedings of the assembly. The remaining five parts have now been published*.

Part 2 deals with the work of Commission II on "Radio and Troposphere". As the chairman's sum-

* International Scientific Radio Union. Proceedings of the 11th General Assembly held in The Hague from August 23rd to September 2nd, 1954. Vol. 10, Part 2. Commission II : Radio and Troposphere Pp. 90, 1956. 100 Belg. fr.; 148. 6d.; 2 dollars. Vol. 10, Part 3. Commission III : Ionospheric Radio. Pp. 194. 1955. 200 Belg. fr. $29 s$, 4 dollars. Vol. 10, Part 5. Commission $\mathrm{V}$ : Radio-Astronomy. Pp. 114. 1955. 125 Belg. fr.; 188.; 2.50 dollars. Vol. 10, Part 6. fr.: 21s. 6 d.; 3 dollars. Vol. 10, Part 7. Commission VII: Radiofr.; 21s. 6d. ; 3 dollars. Vol. 10, Part 7. Commission VII: Radio

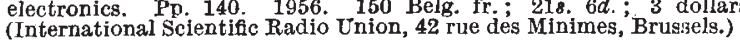

mary of the proceedings shows, this Commission is very active in research on the influence of meteorological conditions on the propagation of radio waves by normal refraction processes to distances well beyond the horizon, and by the phenomena of scattering to distances of several hundred kilcmetres.

"Ionospheric Radio", the title of Commission III, is covered in Part 3. During the general assembly, this Commission held six technical sessions which dealt with the behaviour of the ionosphere at high latitudes, the morphology of the $D$-layer, rocket investigations of the ionosphere, absorption and forward scattering by the ionosphere, and with geomagnetic distortion and storms in the F2-layer. Many of the resolutions of the Commission are concerned with the important and very active part to be played by the International Union in the programme for the forthcoming International Geophysical Year.

The proceedings of the deliberations by Commission V, "Radio-Astronomy", are described in Part 5. The work of this Commission has already resulted in the publication of three special reports (see Nature, December 10, 1955, p. 1110), and the whole subject is being actively pursued on a basis of international co-operation. Sub-commissions have been established to study continuous measurements of solar radio emission, and to explore the possibilities of standardizing equipment and measuring techniques. The importance of making adequate frequency allocations for radio astronomy is emphas. ized; and in the case of such frequency bands as those in which the neutral hydrogen line is located, there is a need for international agreement on such allocations.

Part 6 describes the work carried out at the general assembly by Commission VI on "Radio Waves and Circuits". The resolutions of this Commission show that its work ranges over a wide field, including information and its measurement, the spectra of random signals, band-widths and timeconstants, and the applications of abstract algebra to new circuit arrangements for equipment and antenna systems.

The title of Commission VII is "Radioelectronics", and the report of the chairman given at the end of Part 7 shows that there has been much discussion as to the manner in which the Commission will fit into the general pattern of the International Union. During the meetings, discussions were held on the subjects of solid-state and gaseous electronics, valves for microwave optics and electronics, and on the generation of radiation by gaseous processes; the last being dealt with jointly with Commission $V$ as a subject of mutual interest. A recommendation was made to form a joint commission between the International Scientific Radio Union and the International Union of Pure and Applied Physics to provide means for the discussion of topics in electronics which do not properly belong in the field of radio.

All the publications referred to above contain full details of the scientific sessions, all the national reports in full, together with, in most cases, carefully selected lists of references; the summarizing reports of the respective chairmen with the resolutions of the Commissions adopted at the general assembly are also included. The publication of these remaining parts completes the official record of The Hague meeting of the International Scientific Radio Union, 1954. 